Citation: Dogan, M., "The Effects of Different Sucrose Concentrations on The Regeneration Area of Riccia Fluitans L., A Medicinal Aquatic Plant". Journal of Engineering Technology and Applied Sciences 5 (2) 2020 : 51-58.

\title{
THE EFFECTS OF DIFFERENT SUCROSE CONCENTRATIONS ON THE REGENERATION AREA OF Riccia fluitans L., A MEDICINAL AQUATIC PLANT
}

\author{
Muhammet Dogan \\ Department of Nutrition and Dietetics, Faculty of Health Sciences, Karamanoglu Mehmetbey \\ University, 70100 Karaman, Turkey \\ mtdogan1@gmail.com
}

\begin{abstract}
Carbon sources are very important for plants in vitro growth and development. Sucrose is one of these carbon sources. Determination of sucrose concentration for optimum plant production is required. In this study, the effects of different sucrose concentrations on the in vitro production of the Riccia fluitans L. were investigated. Surface sterilization of the R. fluitans was achieved after $5 \mathrm{~min}$ of application with $15 \%$ hydrogen peroxide. Four-week-old plants grown in sterile culture medium were equally divided and transferred to MS medium supplemented with 0, 5, 10, 20, 30 and $40 \mathrm{mg} / \mathrm{L}$ sucrose and $0.25 \mathrm{mg} / \mathrm{L}$ Zeatin. Plant regeneration values were obtained as $100 \%$ in all culture media. Regeneration area values of R. fluitans were determined between $12.63 \pm 1.79-22.34 \pm 1.82 \mathrm{~cm} 2$. The maximum regeneration area was obtained in MS nutrient medium including $30 \mathrm{~g} / \mathrm{L}$ sucrose $(22.34 \pm 1.82 \mathrm{~cm} 2)$, which is $76.88 \%$ more than control. Generally, the regeneration capacity of the plant increased up to $30 \mathrm{~g} / \mathrm{L}$ sucrose application. The minimum regeneration area value $(12.63 \pm 1.79 \mathrm{~cm} 2)$ was determined in the control group and then recorded in cultures containing $5 \mathrm{mg} / \mathrm{L}$ sucrose $(14.44 \pm 0.92 \mathrm{~cm} 2)$. Plants produced in in vitro conditions were accustomed to external conditions successfully. These results can help the production of R. fluitans with tissue culture techniques.
\end{abstract}

Keywords: Carbon source, in vitro propagation, tissue culture, plant regeneration, sucrose

\section{Introduction}

Today, the term "medicinal" and "aromatic" plants are often used together [1]. However, it is not possible to fully define medicinal plants. Medicinal and aromatic plants are plants used as medicines to prevent diseases, maintain health or cure diseases [2,3]. Medicinal plants are located in areas such as nutrition, cosmetics, body care, incense or religious ceremonies [4]. The compositions obtained from the flowers, leaves, shells or other parts of various medicinal 
plants are increasingly used in the treatment of many diseases in the world, from cancer to diabetes [5].

For sustainable production and market potential in medicinal plants, they must be in the desired quantity and quality. In recent years, developments and diversification in the industry sector based on medicinal plants have attracted attention in Europe [6]. Various scale businesses are based on phytotherapy, aromatherapy, perfumery, cosmetics, herbal teas, health cures, active ingredients and other herbal drugs $[7,8]$. Thanks to these enterprises, the added value of medicinal plants also increases [9].

Riccia fluitans L. (Ricciaceae) is an aquatic plant [10] and has medicinal properties [11]. The healing efficacy of the $R$. fluitans plant on in vivo incision and excision wound models was reported [12]. Riccia species have phytosterol mixtures and acetylene fatty acids [13]. To evaluate the antioxidant and antiradical activities of $R$. fluitans, ABTS radical removal activity, DPPH free radical removal activity, reduction force and iron ions chelation activities were calculated. The results of this study revealed that $R$. fluitans extract had a high antioxidant capacity and contains valuable secondary compounds [11].

One of the most effective methods for the multiple productions of plants is tissue culture. This method includes many advantages for sustainable plant supply [14]. In this study, it was aimed to propagate $R$. fluitans using tissue culture techniques and the effects of different sucrose concentrations on the in vitro production were investigated. According to the literature studies we conducted, no previous study involving different sucrose applications on the production of $R$. fluitans plant under tissue culture conditions has been determined. Therefore, the current study can make an important contribution to the literature in this field.

\section{Material and methods}

Plant material ( $R$. fluitans) was supplied from aquarium plants store in Istanbul/Turkey. The surface sterilization of plants was accomplished with 5 minutes of application with 15\% hydrogen peroxide $\left(\mathrm{H}_{2} \mathrm{O}_{2}-35 \%\right.$ Merck Millipore). The sterile thallus parts were cultured in MS food medium (Murashige and Skoog, [15]) without growth regulator. Regeneration studies have been started with the new plants obtained.

Four-week-old plants grown in this culture medium were equally divided and transferred to MS medium supplemented with 0, 5, 10, 20, 30 and $40 \mathrm{mg} / \mathrm{L}$ sucrose and $0.25 \mathrm{mg} / \mathrm{L}$ Zeatin. 0.65\% agar was also used in the culture media. Pure water was used in the preparation of the nutrient medium. The $\mathrm{pH}$ of the medium was adjusted to $5.7 \pm 1.0$ via $1 \mathrm{~N} \mathrm{NaOH}$ and $1 \mathrm{~N} \mathrm{HCI}$. Afterwards, it was kept at 1.2 atmospheric pressure $\left(120^{\circ} \mathrm{C}\right)$ for 20 min for sterilization. In experiments, the plant parts (explants) were incubated at a temperature of $24{ }^{\circ} \mathrm{C}$ and a 16 -hour light photodiode with white Light Emitting Diodes (LEDs) light (1500 lux). After eight weeks, the plants growing and growing were obtained and the trial was terminated. Plants produced in in vitro conditions are accustomed to external conditions in beakers with water. Aquatic conditions were set at $24^{\circ} \mathrm{C}$ and 16 hours of illumination.

All trials were carried out in three replicates in plastic petri dishes. Regeneration data were analyzed with SPSS 21 for Windows (Statistical Package for Social Sciences). Duncan test was performed for Post Hoc. Regeneration values were considered significant at $p<0.05$. Also, the means of the Upper Link (UB) and Lower Link (LB) were specified. 


\section{Results and discussion}

Plant production is increasing day by day with tissue culture techniques. Many plant species such as Bacopa monnieri L. Pennell [16], Cannabis sativa L. [17] and Malus sieversii [18] have been successfully produced with this method.

The use of sucrose and the concentration of sucrose is an important factor in success in in vitro propagation studies. It was previously explained that the plants cultivated display different regeneration characteristics depending on the sucrose concentrations [19,20,21]. In the current study, the effects of sucrose application at different concentrations in tissue culture conditions on the regeneration field of $R$. fluitans were evaluated. Differences were detected in the second week on the explants in the petri dishes. After four weeks, $R$. fluitans plants showed marked growth. After growing regenerated plants, trials were terminated at the eighth week (Figure 1). Variance analysis was done with regeneration data (Table 1).

Table 1. Tests of between-subjects impacts for various sucrose applications

\begin{tabular}{|l|c|c|c|c|c|}
\hline Source & $\begin{array}{c}\text { Type III Sum } \\
\text { of Squares }\end{array}$ & df & Mean Square & F & Sig. \\
\hline Corrected Model & $200.404(\mathrm{a})$ & 5 & 40.081 & 17.296 & 0.000 \\
Intercept & 5626.483 & 1 & 5626.483 & 2428.034 & 0.000 \\
Medium & 200.404 & 5 & 40.081 & 17.296 & 0.000 \\
Error & 27.808 & 12 & 2.317 & & \\
Total & 5854.695 & 18 & & & \\
Corrected Total & 228.212 & 17 & & & \\
\hline
\end{tabular}

a R Squared $=0.878$ 


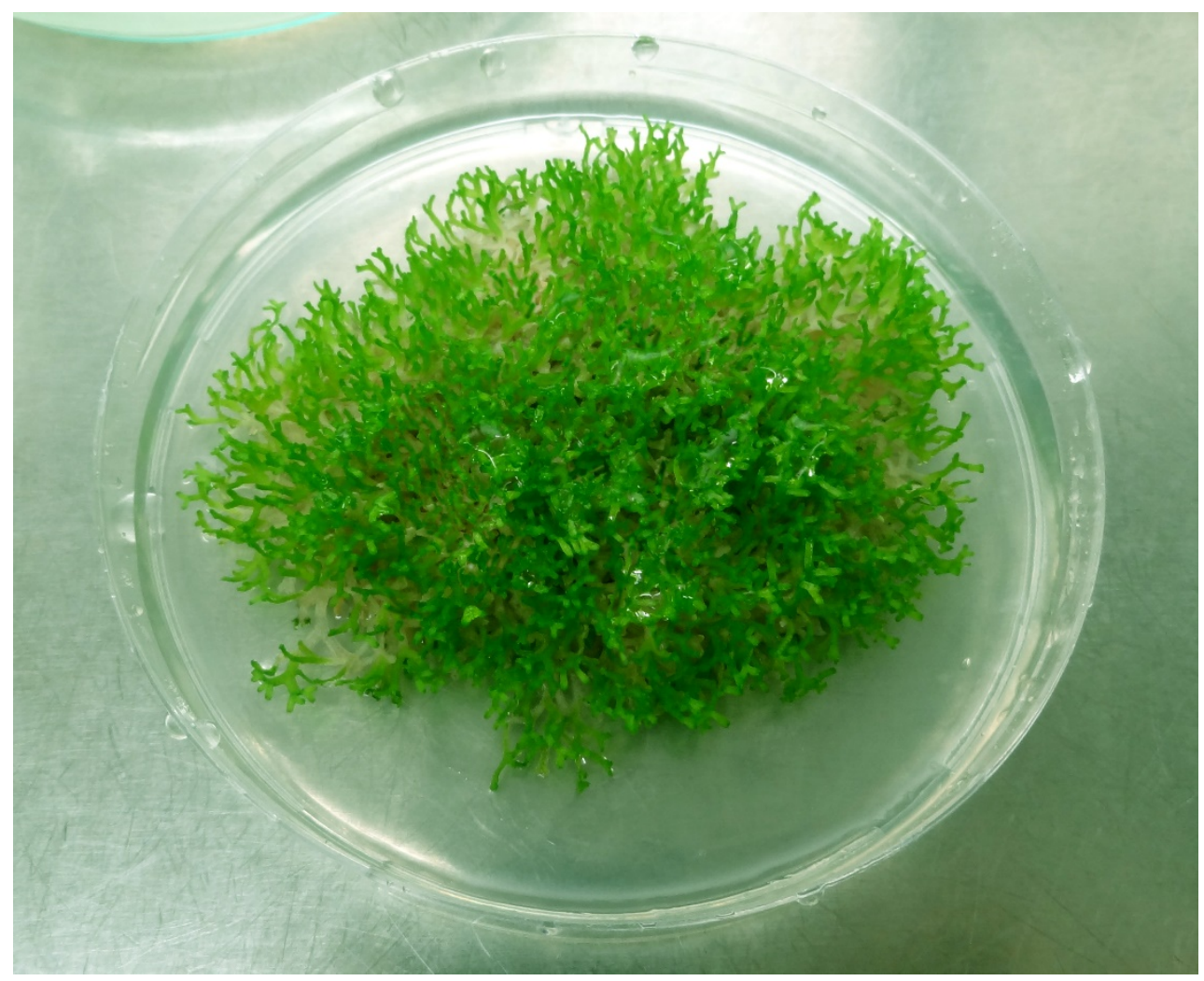

Figure 1. The regeneration of $R$. fluitans in the culture medium including $30 \mathrm{~g} / \mathrm{L}$ sucrose concentration

According to the analysis results given in Table 1 , regeneration area values were found statistically significant at the level of $95 \%$ in terms of different sucrose values $\left(\mathrm{R}^{2}: 0.878 ; \mathrm{F}\right.$ : 17.296). The Duncan test was used to designate the extent of this significance (Table 2).

Table 2. Effect of various sucrose applications on regeneration area of $R$. Fluitans

\begin{tabular}{|c|c|c|c|c|}
\hline \multirow{3}{*}{$\begin{array}{c}\text { Sucrose } \\
\text { concentration } \\
\text { (g/L) }\end{array}$} & \multirow{3}{*}{$\begin{array}{c}\text { Frequency of } \\
\text { regeneration (\%) }\end{array}$} & \multicolumn{3}{|c|}{ Regeneration area $\left(\mathrm{cm}^{2}\right)$} \\
\hline & & \multirow[b]{2}{*}{ Mean } & \multicolumn{2}{|c|}{$95 \%$ confidence interval } \\
\hline & & & $\begin{array}{l}\text { Lower } \\
\text { bound }\end{array}$ & Upper bound \\
\hline $\mathbf{0}$ & 100 & $12.63 \pm 1.79 \mathrm{e}$ & 10.715 & 14.545 \\
\hline 5 & 100 & $14.44 \pm 0.92 \mathrm{de}$ & 12.528 & 16.358 \\
\hline 10 & 100 & $17.14 \pm 1.14^{\mathrm{cd}}$ & 15.225 & 19.055 \\
\hline 20 & 100 & $20.02 \pm 1.19 \mathrm{ab}$ & 18.108 & 21.938 \\
\hline 30 & 100 & $22.34 \pm 1.82^{\mathrm{a}}$ & 20.425 & 24.255 \\
\hline 40 & 100 & $19.50 \pm 1.94$ bc & 17.588 & 21.418 \\
\hline
\end{tabular}

Different letters refer significant differences at the level of $p<0.05$. 
Plant regeneration frequencies were determined as $100 \%$ in all culture vessels. These results showed us that the $R$. fluitans plant had a high regeneration capacity. On the other hand, regeneration values may vary widely in some plants. Toaima et al. [22] cultured the nodal explants of Gypsophila paniculata L. for four weeks in a nutrient medium including different concentrations of sucrose and recorded shoot regeneration frequencies between 50-94.4\%.

Regeneration area values of $R$. fluitans varied between $12.63 \pm 1.79-22.34 \pm 1.82 \mathrm{~cm}^{2}$ and statistically significant at $p<0.05$ level (Table 2). The highest regeneration area was obtained in MS nutrient medium with $30 \mathrm{~g} / \mathrm{L}$ sucrose (22.34 $\pm 1.82 \mathrm{~cm}^{2}$; LB: 20.425 - UB: 24.255) followed by MS nutrient medium with $20 \mathrm{mg} / \mathrm{L}$ sucrose $\left(20.02 \pm 1.19 \mathrm{~cm}^{2}\right.$; LB: 18.108 - UB: 21.938). Generally, the regeneration capacity of the plant increased up to $30 \mathrm{~g} / \mathrm{L}$ sucrose application. The use of sucrose higher $(40 \mathrm{~g} / \mathrm{L})$ than this value negatively affected the regeneration capacity. The results showed that regeneration areas obtained from the use of 30 $\mathrm{g} / \mathrm{L}$ and $20 \mathrm{~g} / \mathrm{L}$ sucrose were statistically insignificant $(p>0.05)$. The lowest regeneration area value (12.63 $\pm 1.79 \mathrm{~cm}^{2}$; LB: 10.715 - UB: 14.545) was determined in the control group. In environments containing sucrose, the lowest value was recorded as $14.44 \pm 0.92 \mathrm{~cm}^{2}$ (LB: 12.528 - UB: 16.358) in $5 \mathrm{~g} / \mathrm{L}$ sucrose application. Similarly, Srivastava et al. [23] transferred the nodal and leaf explants of Bacopa monnieri (L.) Wettst. to a culture medium with sucrose added at a level of $0.5-10 \%$ and determined the maximum number of shoots in nodal explants as $22.6 \pm 0.31$ shoots/explant in cultures with $5 \%$ sucrose and $20.6 \pm 0.35$ shoots/explant in cultures with $3 \%$ sucrose in leaf explants. In addition, it was reported that there was no shoot exodus in cultures containing the highest level of sucrose (10\%). Naik et al. [24] investigated the effect of different sucrose concentrations (0-6\%) on shoot regeneration of the B. monnieri plant from leaf explants and reached the highest number of shoots ( $79.00 \pm 2.30$ shoots/explant) at a $2 \%$ sucrose concentration. They recorded the least number of shoots in the control group (6.66 \pm 0.24$)$ and in application of $1 \%$ sucrose (22.25 \pm 0.13$)$. Nhut et al. [25] placed young stem parts of Lilium longiflorum Thunb. in a nutrient medium containing different sucrose concentrations (10-30 g/L) and achieved a high number of shoots and best regeneration in cultures with $30 \mathrm{~g} L$ sucrose ( $8.9 \pm 0.2$ shoots/explant). The least number of shoots were detected in $10 \mathrm{~g} / \mathrm{L}$ sucrose application (2.2 \pm 0.1 shoots/explant). Ayub et al. [26] cultured the node and internodes of the blackberry (Rubus spp. L.) in a nutrient environment containing $1 \mathrm{mg} / \mathrm{L}$ BAP and 10-40 g/L sucrose and obtained the best regeneration values at a concentration of $20 \mathrm{~g} / \mathrm{L}$ sucrose. Jeong and Sivanesan [27] cultured leaf explants of Ajuga multiflora Bunge under a different light (blue LED, red LED and White fluorescent light) and sucrose applications (0$3 \%)$ and reached high regeneration numbers under White fluorescent light and $2 \%$ sucrose application (34.8 \pm 2.9 ). Rasheed and Yaseeen [28] reported that the application of 3\% sucrose was the most suitable concentration for the production of Asparagus densiflorus (Kunth) Jessop cv Sprengeri. These results revealed that the sucrose concentration in nutrient media was important for the regeneration properties of explants and may show different results depending on the plant species.

As a result of sucrose applications, the average of all regeneration values was obtained as 17.680 $\pm 0.359 \mathrm{~cm}^{2}$ (LB: 16.898 - UB: 18.462) (Table 3). In Figure 2, the percentage differences of the regeneration values in the nutrient media containing different sucrose applications compared to the control group were presented. According to the control, the most increases in the regeneration area were listed as $30 \mathrm{~g} / \mathrm{L}(76.88 \%)>20 \mathrm{~g} / \mathrm{L}(58.51 \%)>40 \mathrm{~g} / \mathrm{L}(54.39 \%)>10$ $\mathrm{g} / \mathrm{L}(35.71 \%)>5 \mathrm{~g} / \mathrm{L}(14.33 \%)$. 
Table 3. Average of regeneration areas obtained by different sucrose applications

\begin{tabular}{|c|c|c|c|}
\hline \multirow{2}{*}{ Average } & \multirow{2}{*}{ Std. Error } & \multicolumn{2}{|c|}{ 95\% Confidence Interval } \\
\hline & & Lower Bound & Upper Bound \\
\hline 17.680 & 0.359 & 16.898 & 18.462 \\
\hline
\end{tabular}

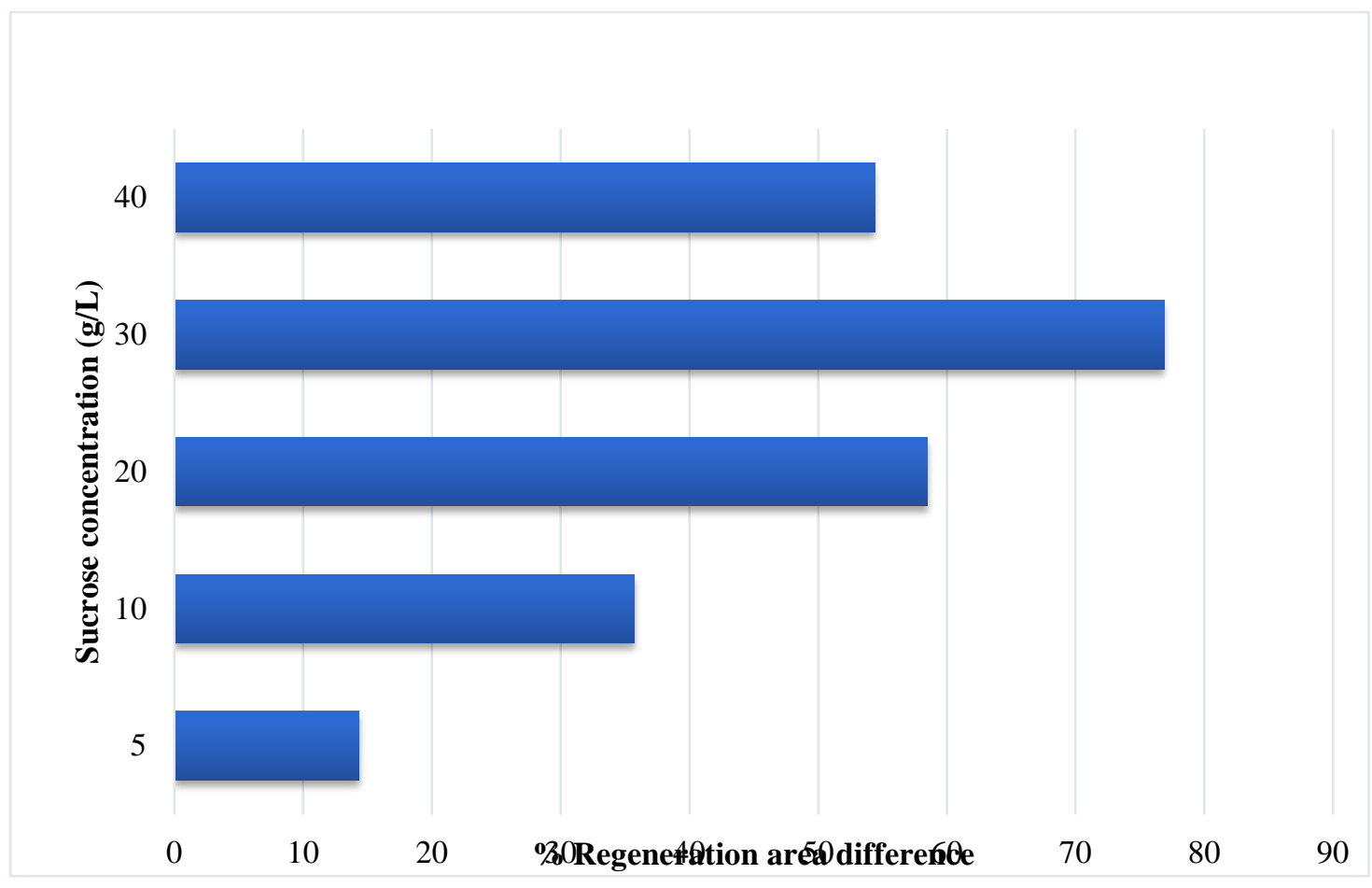

Figure 2. Percentage display of regeneration area differences compared to the control group

Plants produced with the effect of sucrose in the culture medium were prepared to acclimate to ex vitro conditions. Nutrient media containing agar on plants was carefully cleaned with tap water. Then it was transferred to beakers with water and the plants were successfully adapted to external conditions after three weeks.

\section{Conclusion}

Carbon sources are indispensable factors of tissue culture. In this study, different sucrose concentrations were used as a carbon source and in vitro regeneration area of $R$. fluitans was determined. The highest regeneration area was achieved with the application of $30 \mathrm{~g} / \mathrm{L}$ sucrose, which was $76.88 \%$ higher than the control. The results showed that sucrose doses were important for multiple in vitro production of plants. These results can help the production of $R$. fluitans with tissue culture techniques. It can also contribute to academics working in this field. 


\section{References}

[1] Lubbe, A., Verpoorte, R., "Cultivation of medicinal and aromatic plants for specialty industrial materials”, Industrial Crops and Products 34(1) (2011) : 785-801.

[2] Inoue, M., Hayashi, S., Craker, L.E., "Role of medicinal and aromatic plants: Past, present, and future”, In Pharmacognosy-Medicinal Plants, IntechOpen (2019).

[3] Sevindik, M., Akgul, H., Pehlivan, M., Selamoglu, Z., "Determination of therapeutic potential of Mentha longifolia ssp. longifolia”, Fresenius Environmental Bulletin 26 (2017) : 4757-4763.

[4] Muñoz-Acevedo, A., Torres, E.A., Gutiérrez, R.G., Cotes, S.B., Cervantes-Díaz, M., Tafurt-García, G., "Some Latin American plants promising for the cosmetic, perfume and flavor industries”. Therapeutic Medicinal Plants: From Lab to the Market; Duarte, M.C.T., Rai, M., Eds, (2015) : 279-330.

[5] Pierre, S., Alex, N.N., Jean, M., "Medicinal plants used in traditional treatment of malaria in Cameroon”, Journal of Ecology and the Natural Environment 3(3) (2011) : 104-117.

[6] De Oliveira Martins, D.T., Rodrigues, E., Casu, L., Benítez, G., Leonti, M., “The historical development of pharmacopoeias and the inclusion of exotic herbal drugs with a focus on Europe and Brazil”, Journal of ethnopharmacology 240 (2019) : 111891.

[7] Anwar, F., Abbas, A., Mehmood, T., Gilani, A.H., Rehman, N.U., "Mentha: A genus rich in vital nutra-pharmaceuticals-A review”, Phytotherapy Research 33(10) (2019) : 25482570 .

[8] Nemethy, S., Takacs, T., Szemethy, L., Lagerqvist, B., Barocsi, Z., Dinya, A., Peterffy, I., "Collection, cultivation and processing of medical plants, herbs and spices in the Balaton Ecomuseum-herbal medicine as intangible cultural heritage”, Ecocycles 6(1) (2020) : 52-87.

[9] Bayram, E., Kırıcı, S., Tansi, S., Yılmaz, G., Kızıl, O.A.S., Telci, İ., “Tibbi ve aromatik bitkiler üretiminin arttırılması olanakları”, TMMOB Ziraat Mühendisleri Odasi, Ziraat Mühendisligi VII. Teknik Kongresi (2010) : 11-15.

[10] Kwon, W., Min, J., Xi, H., Park, J., “The complete chloroplast genome of Riccia fluitans L. (Ricciaceae, Marchantiophyta)”, Mitochondrial DNA Part B 4(1) (2019) : 1895-1896.

[11] Türkoğlu, S., Parlak, A.E., "Determination of total phenolic and total flavonoid contents and antioxidant capacities of an aquatic plant (Riccia fluitans)”, Su Ürünleri Dergisi 31(1) (2014) : 35-40.

[12] Tosun, A., Süntar, İ., Keleş, H., Kiremit, H.Ö., Asakawa, Y., Akkol, E.K., "Wound healing potential of selected Liverworts", Turkish Journal of Pharmaceutical Sciences 13(3) (2016) : 285-291.

[13] Asakawa, Y., "Chemosystematics of the Hepaticae”, Phytochemistry 65(6) (2004) : 623669.

[14] Shahzad, A., Sharma, S., Parveen, S., Saeed, T., Shaheen, A., Akhtar, R., Yadav, V., Upadhyay, A., Ahmad, Z. "Historical perspective and basic principles of plant tissue culture. In Plant biotechnology: Principles and applications”, Springer, Singapore, (2017) : $1-36$.

[15] Murashige. T., Skoog, F., "A revised medium for rapid growth and bioassays with tobacco tissue cultures”, Physiologia Plantarum 15 (1962) : 473-497. 
[16] Dogan, M., Emsen, B., "Anti-cytotoxic-genotoxic influences of in vitro propagated Bacopa monnieri L. Pennell in cultured human lymphocytes”, Eurasian Journal of Biological and Chemical Sciences 1(2) (2018) : 48-53.

[17] Galán-Ávila, A., García-Fortea, E., Prohens, J., Herraiz, F.J., "Development of a direct in vitro plant regeneration protocol from Cannabis sativa L. seedling explants: Developmental morphology of shoot regeneration and ploidy level of regenerated plants”, Frontiers in Plant Science 11 (2020) : 645.

[18] Zhang, Y., Bozorov, T.A., Li, D.X., Zhou, P., Wen, X.J., Ding, Y., Zhang, D.Y., “An efficient in vitro regeneration system from different wild apple (Malus sieversii) explants”, Plant Methods 16 (2020) : 1-10.

[19] Vinterhalter, D.V., Vinterhalter, B.S., "Hormone-like effects of sucrose in plant in vitro cultures”, Phyton 39(3) (1999) : 57-60.

[20] Gabryszewska, E.A., "Effect of different sucrose and nitrogen salt levels in the medium and temperature on in vitro propagation of Helleborus niger L.”, Acta Agrobotanica 68(2) (2015) : 161-171.

[21] Dogan, M., “In vitro shoot regeneration performance of Pogostemon erectus (Dalzell) Kuntze in culture medium containing different sucrose concentrations", International Journal of Eastern Mediterranean Agricultural Research, 2(1) (2019) : 1-12.

[22] Toaima, N., Bosila, H., El-Ateeq, A.A.E.F., "In vitro growth regulators, gelling agents and sucrose levels affect micropropagation of Gypsophila paniculata L.”, Middle East Journal 5(3) (2016) : 313-323.

[23] Srivastava, P., Tiwari, K.N., Srivastava, G., "Effect of different carbon sources on in vitro regeneration of Brahmi Bacopa monnieri (L.) An important memory vitalizer”, Journal of Medicinal Plants Research 5(3) (2017) : 202-208.

[24] Naik, P.M., Manohar, S.H., Praveen, N., Murthy, H.N., "Effects of sucrose and pH levels on in vitro shoot regeneration from leaf explants of Bacopa monnieri and accumulation of bacoside A in regenerated shoots”, Plant Cell, Tissue and Organ Culture (PCTOC) 100(2) (2010) : 235-239.

[25] Nhut, D.T., Van Le, B., Fukai, S., Tanaka, M., Van, K.T.T., "Effects of activated charcoal, explant size, explant position and sucrose concentration on plant and shoot regeneration of Lilium longiflorum via young stem culture”, Plant Growth Regulation 33(1) (2001) : 59-65.

[26] Ayub, R.A., Santos, J.N.D., Zanlorensi Junior, L.A., Silva, D.M.D., Carvalho, T.C.D., Grimaldi, F., "Sucrose concentration and volume of liquid medium on the in vitro growth and development of blackberry cv. Tupy in temporary immersion systems”, Ciência e Agrotecnologia (2019) : 43.

[27] Jeong, B.R., Sivanesan, I., "Impact of light quality and sucrose on adventitious shoot regeneration and bioactive compound accumulation in Ajuga multiflora Bunge”, Scientia Horticulturae 236 (2018) : 222-228.

[28] Rasheed, K.A., Yaseen, S.A., "In vitro shoot multiplication of Asparagus densiflorus as affected by media, sucrose and ph”, International Journal of Pure and Applied Sciences and Technology 17 (2013) : 28-35. 